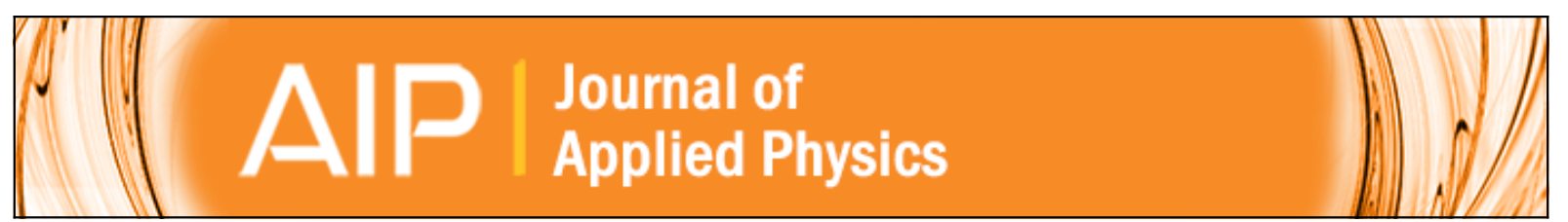

\title{
Structural analysis of silicon co-implanted with carbon and high energy proton for the formation of the lasing G-centre
}

D. D. Berhanuddin, M. A. Lourenço, C. Jeynes, M. Milosavljević, R. M. Gwilliam, and K. P. Homewood

Citation: Journal of Applied Physics 112, 103110 (2012); doi: 10.1063/1.4766390

View online: http://dx.doi.org/10.1063/1.4766390

View Table of Contents: http://scitation.aip.org/content/aip/journal/jap/112/10?ver=pdfcov

Published by the AIP Publishing

\section{Articles you may be interested in}

Lithium implantation at low temperature in silicon for sharp buried amorphous layer formation and defect engineering

J. Appl. Phys. 113, 083515 (2013); 10.1063/1.4793507

Influence of preamorphization on the structural properties of ultrashallow arsenic implants in silicon

J. Appl. Phys. 100, 103533 (2006); 10.1063/1.2363252

Damage accumulation in neon implanted silicon

J. Appl. Phys. 100, 043505 (2006); 10.1063/1.2220644

Influence of in situ ultrasound treatment during ion implantation on amorphization and junction formation in silicon J. Vac. Sci. Technol. B 20, 1448 (2002); 10.1116/1.1493784

High dose rate effects in silicon by plasma source ion implantation

J. Vac. Sci. Technol. B 17, 863 (1999); 10.1116/1.590652

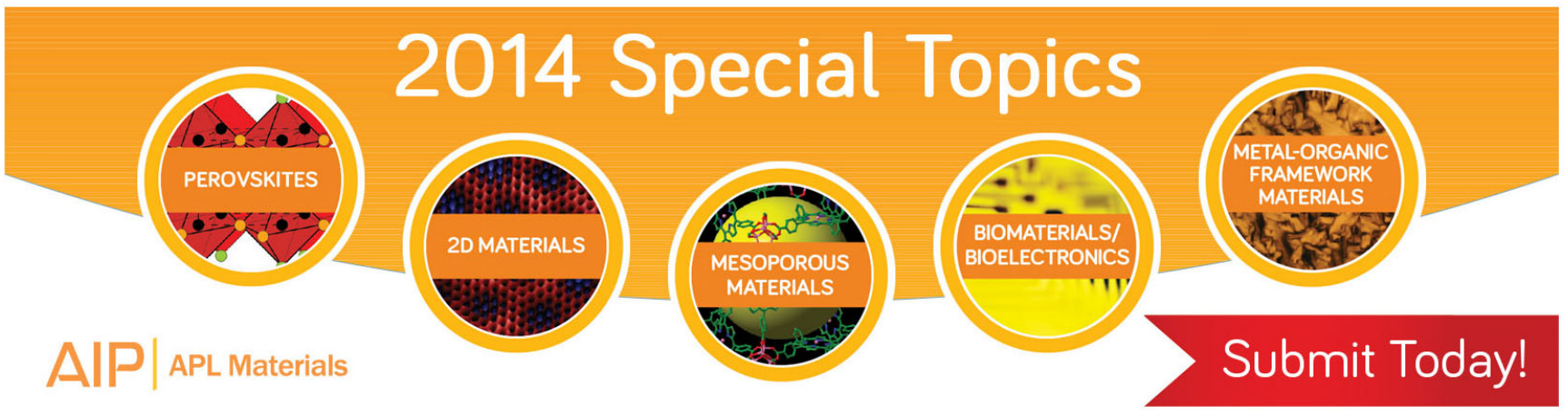




\title{
Structural analysis of silicon co-implanted with carbon and high energy proton for the formation of the lasing G-centre
}

\author{
D. D. Berhanuddin, ${ }^{1,2}$ M. A. Lourenço, ${ }^{1, a)}$ C. Jeynes, ${ }^{1}$ M. Milosavljević, ${ }^{1,3}$ R. M. Gwilliam, ${ }^{1}$ \\ and K. P. Homewood ${ }^{1}$ \\ ${ }^{1}$ Advanced Technology Institute, Faculty of Engineering and Physical Sciences, University of Surrey, \\ Guildford, Surrey GU2 7XH, United Kingdom \\ ${ }^{2}$ Institute of Microengineering and Nanoelectronics, Universiti Kebangsaan Malaysia, Bangi, 43000 Selangor, \\ Malaysia \\ ${ }^{3}$ VINČA Institute of Nuclear Sciences, Belgrade University, P. O. Box 522, 11001 Belgrade, Serbia
}

(Received 16 October 2012; accepted 20 October 2012; published online 21 November 2012)

\begin{abstract}
We investigate a new approach for efficient generation of the lasing G-centre (carbon substitutional-silicon self-interstitial complex) which crucially is fully compatible with standard silicon ultra-large-scale integration technology. Silicon wafers were implanted with carbon and irradiated with high energy protons to produce self-interstitials that are crucial in the formation of the G-centre. Rutherford backscattering spectrometry (RBS) and transmission electron microscopy were used to study the structure of the post-implanted silicon samples and to investigate the behaviour of the self-interstitials and damage introduced by the carbon and proton implantation. The effect of substrate pre-amorphisation on the G-centre luminescence intensity and formation properties was also investigated by implanting Ge prior to the carbon and proton irradiation. Photoluminescence measurements and RBS results show a significantly higher G-centre peak intensity and silicon yield, respectively, in samples without pre-amorphisation. (C) 2012 American Institute of Physics. [http://dx.doi.org/10.1063/1.4766390]
\end{abstract}

\section{INTRODUCTION}

Silicon photonics is an exciting, rapidly developing field which holds the future to fast computer chips and telecommunication by integration of optical components with electronics. There is also an urgent requirement to create a silicon-based optical emitter which is compatible with standard ultra large scale integration (ULSI) technology used in fabricating integrated circuits. Despite the silicon indirect bandgap, which makes it unsuitable as an optical emitter, in the past decade, various approaches have been attempted to try circumventing the bandgap limitation, thus, transforming silicon as an optically active material. Among the successful and promising methods of obtaining light emission from silicon is the manipulation of point defect centers to produce emission at certain wavelengths. ${ }^{1-5}$

The G-centre as an emissive point defect gained attention recently due to its sharp zero phonon line luminescence peak at the wavelength of $1.28 \mu \mathrm{m}(0.97 \mathrm{eV})$ and evidence that lasing can occur. ${ }^{4}$ The G-centre emission is attributed to the carbon substitutional-carbon interstitial $\left(\mathrm{C}_{s} \mathrm{C}_{i}\right)$ complex which interacts with silicon interstitials during radiation damage events. ${ }^{6}$ The G-centre emission at $1.28 \mu \mathrm{m}$ is in the spectral range which is vital in long-haul fiber-optic networks and as it is below the Si bandgap energy, it is attractive for silicon intra-chip and inter-chip low-power data interconnects. Earlier reports showed that the G-centre emission could be enhanced by pre-amorphisation of the silicon substrate and solid-phase epitaxial regrowth technique. ${ }^{3}$ This approach increased the carbon solubility at the interface

\footnotetext{
a) Author to whom correspondence should be addressed. Electronic mail: m.lourenco@surrey.ac.uk.
}

between crystalline and amorphous silicon and, combined with nanopatterning of the surface of $\mathrm{C}$-enriched silicon, significantly increased the G-centre luminescence intensity.

A new method fully compatible with complementary metal oxide semiconductor (CMOS) technology to efficiently produce the lasing G-centre has been recently reported. $^{7}$ It combines the implantation of carbon, subsequent heat treatment followed by high energy proton implantation to form $\mathrm{C}_{s} \mathrm{C}_{i}$ complexes and $\mathrm{Si}$ interstitials. The luminescence intensity of the G-centre emission varies with the implant conditions such as the carbon and proton doses.

In this paper we used photoluminescence (PL), Rutherford backscattering spectrometry (RBS) and transmission electron microscopy (TEM) techniques to correlate the optical and structural properties of the G-centre formed by ion implantation. Photoluminescence measurements were carried out on crystalline and pre-amorphised silicon samples implanted with different doses of carbon and protons. Preamorphisation of the silicon substrate was achieved by Ge implantation prior to the $\mathrm{C}$ implantation. RBS and RBSchannelling experiments were performed to analyse the damage distribution caused by the silicon interstitials and to quantify defect production due to the carbon and high energy proton implantation, respectively. TEM was also utilized to characterize the type and composition of damage present in the samples.

\section{SAMPLE PREPARATION AND ANALYSIS}

N-type silicon wafers (100) with resistivity of $\sim 10 \Omega$ $\mathrm{cm}^{-1}$ and manufacturer specified residual $\mathrm{C}$ concentration of $2.5 \times 10^{16} \mathrm{~cm}^{-3}$ were double implanted with different carbon doses, first at $30 \mathrm{keV}$, and followed by a second implantation 
at $10 \mathrm{keV}$. The double implantations were used to form a flat carbon profile, thus, ensuring better uniformity of carbon concentration along the depth of samples. The carbon volume concentration after both implantations ranged from $2 \times 10^{18}$ to $2 \times 10^{20} \mathrm{~cm}^{-3}$ calculated using SUSPRE. ${ }^{8}$ Samples were also fabricated by $\mathrm{C}$ implantation into $\mathrm{Si}$ substrates preamorphised with $2 \times 10^{15} \mathrm{Ge} \mathrm{cm}^{-2}$ implantation at $180 \mathrm{keV}$. After the $\mathrm{C}$ implantation, samples were annealed at $1000^{\circ} \mathrm{C}$ for $20 \mathrm{~s}$ in $\mathrm{N}_{2}$ ambient to repair the lattice damage and to introduce the carbon into the substitutional sites. Proton irradiation of the annealed samples was subsequently carried out at fluences of either $5 \times 10^{12} \mathrm{~cm}^{-2}, 5 \times 10^{13} \mathrm{~cm}^{-2}$, or $5 \times 10^{15} \mathrm{~cm}^{-2}$ at $2 \mathrm{MeV}$. A non-implanted silicon wafer was kept as a reference. Details of the samples are given in Table I.

PL measurements were performed at $80 \mathrm{~K}$ across the $1.0-1.7 \mu \mathrm{m}$ spectral region with samples mounted in a continuous flow liquid $\mathrm{N}_{2}$ cryostat. The PL was excited by an Ar-ion laser line at $514.5 \mathrm{~nm}$ at a power density of $\sim 5 \mathrm{~mW}$ $\mathrm{mm}^{-2}$.

RBS analysis was performed using $1.285 \mathrm{MeV}^{4} \mathrm{He}^{+}$ion beam and a beam current of $\sim 20 \mathrm{nA}$. The spectral plots show the normalised backscattered yield collected from the two surface barrier detectors placed at $148.2^{\circ}$ and $172.8^{\circ}$ scattering angles. Depth profiles used in this work can be extracted automatically from RBS spectra using the Surrey IBA Data Furnace software, ${ }^{9}$ the accuracy of which has been validated against a certified standard sample. ${ }^{10}$

TEM and XTEM (cross-sectional TEM) analysis were done using Philips EM400T and CM200 electron microscopes, operated at 120 and $200 \mathrm{kV}$, respectively. Both cross-sectional and plan-view specimens of all samples were prepared using low-angle argon ion-beam thinning at $5 \mathrm{keV}$.

\section{RESULTS AND DISCUSSION}

Figure 1 shows the photoluminescence spectra of preamorphised samples implanted to $2 \times 10^{20} \mathrm{C} \mathrm{cm}^{-3}$ volume concentration followed by proton irradiation at $5 \times 10^{13}$ $\mathrm{cm}^{-2}$ (sample A03) and $5 \times 10^{15} \mathrm{~cm}^{-2}$ (sample A05). The G-centre's peak at $1280 \mathrm{~nm}$ is present in both samples with the highest intensity being observed in sample A03. The

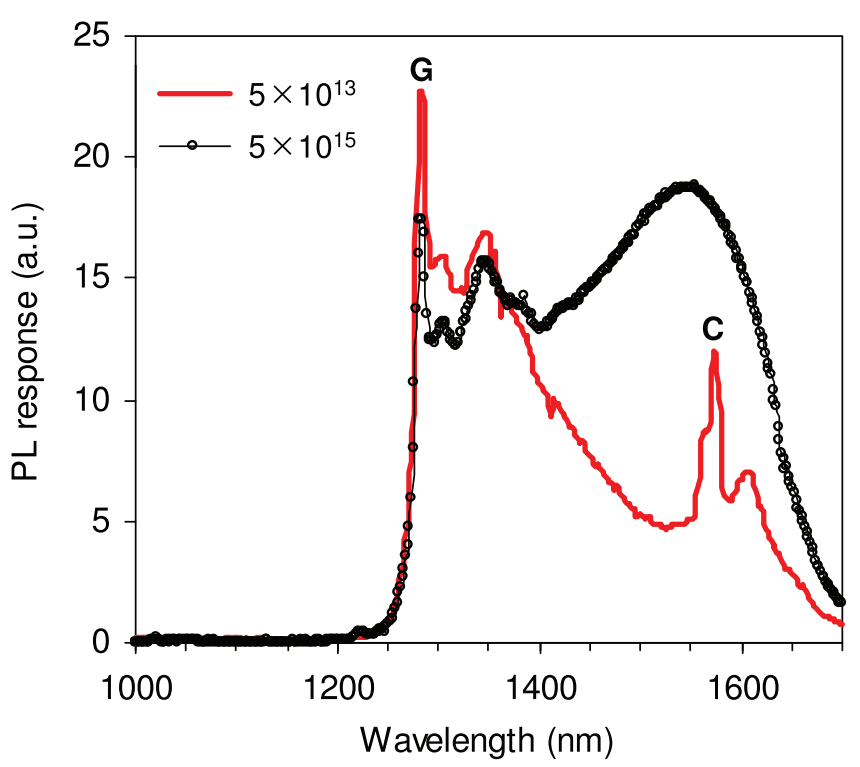

FIG. 1. Photoluminescence spectra, observed at $80 \mathrm{~K}$, of pre-amorphised silicon samples A03 and $\mathrm{A} 05\left(2 \times 10^{20} \mathrm{C} \mathrm{cm}^{-3}\right.$ irradiated with $5 \times 10^{13}$ and $5 \times 10^{15} \mathrm{H}^{+} \mathrm{cm}^{-2}$, respectively). The positions of the G- and C-centres are also shown.

irradiation with protons at the higher dose (sample A05) results in an excess of self-interstitials in the interstices which then compete to form different types of damage centres, thus lowering the G-centre peak intensity while developing a dominant, broad peak in the $\sim 1400$ to $1600 \mathrm{~nm}$ range. The broader structured luminescence from 1.3 to $1.4 \mu \mathrm{m}$ observed in both spectra is a familiar feature of the G-line spectra resulting from local phonon modes. ${ }^{11}$ Another zero phonon line luminescence feature is observed at $\sim 1.57 \mu \mathrm{m}$ in the sample implanted with $5 \times 10^{13} \mathrm{H}^{+} \mathrm{cm}^{-2}$ and is attributed to the carbon-oxygen $\left(\mathrm{C}_{\mathrm{i}} \mathrm{O}_{\mathrm{i}}\right)$ complex (C-line). ${ }^{12,13}$

Figure 2 shows the RBS channelling spectra along the [001] Si direction for the same samples of Figure 1 as well as a channelled spectrum of a virgin silicon sample (reference sample). The reference sample shows the good quality of the silicon crystal. The peak observed around channel 120 in all samples is related to a small oxide layer $(\sim 2 \mathrm{~nm}$ for the

TABLE I. Sample details. All pre-amorphised samples were implanted with $\mathrm{Ge}$ at $180 \mathrm{keV}$ prior to the $\mathrm{C}$ implantation. The first carbon implant $\left(\mathrm{CI}_{1}\right)$ was at $30 \mathrm{keV}$ and the second implant $\left(\mathrm{CI}_{2}\right)$ at $10 \mathrm{keV}$. All samples were annealed at $1000^{\circ} \mathrm{C}$ for $20 \mathrm{~s}$ after the $\mathrm{C}$ implants. The average carbon volume concentrations were calculated using SUSPRE. ${ }^{8}$ Proton irradiation was performed at $2 \mathrm{MeV}$ after the $\mathrm{C}$ post-implant anneal. No further sample processing was done after the proton irradiation. The samples are labeled according to the processing conditions: $\mathrm{C}$ for crystalline and A for pre-amorphised Si substrates; 8,9 , and 0 for $10^{18}, 10^{19}$, and $10^{20} \mathrm{C} \mathrm{cm}^{-3}$, respectively; 2,3 , and 5 for proton irradiation at $10^{12}, 10^{13}$, and $10^{15} \mathrm{H}^{+} \mathrm{cm}^{-2}$, respectively.

\begin{tabular}{|c|c|c|c|c|c|}
\hline Sample & Ge dose $\left(\mathrm{cm}^{-2}\right)$ & $\mathrm{CI}_{1}$ dose $\left(\mathrm{cm}^{-2}\right)$ & $\mathrm{CI}_{2}$ dose $\left(\mathrm{cm}^{-2}\right)$ & C volume concentration $\left(\mathrm{cm}^{-3}\right)$ & Proton dose $\left(\mathrm{cm}^{-2}\right)$ \\
\hline A0 & $2 \times 10^{15}$ & $2 \times 10^{15}$ & $5.5 \times 10^{14}$ & $2 \times 10^{20}$ & $\ldots$ \\
\hline $\mathrm{A} 03$ & $2 \times 10^{15}$ & $2 \times 10^{15}$ & $5.5 \times 10^{14}$ & $2 \times 10^{20}$ & $5 \times 10^{13}$ \\
\hline A05 & $2 \times 10^{15}$ & $2 \times 10^{15}$ & $5.5 \times 10^{14}$ & $2 \times 10^{20}$ & $5 \times 10^{15}$ \\
\hline $\mathrm{C} 83$ & $\ldots$ & $2 \times 10^{13}$ & $5.5 \times 10^{12}$ & $2 \times 10^{18}$ & $5 \times 10^{13}$ \\
\hline C93 & $\ldots$ & $2 \times 10^{14}$ & $5.5 \times 10^{13}$ & $2 \times 10^{19}$ & $5 \times 10^{13}$ \\
\hline $\mathrm{C} 03$ & $\ldots$ & $2 \times 10^{15}$ & $5.5 \times 10^{14}$ & $2 \times 10^{20}$ & $5 \times 10^{13}$ \\
\hline $\mathrm{C} 0$ & $\ldots$ & $2 \times 10^{15}$ & $5.5 \times 10^{14}$ & $2 \times 10^{20}$ & $\ldots$ \\
\hline $\mathrm{C} 02$ & $\ldots$ & $2 \times 10^{15}$ & $5.5 \times 10^{14}$ & $2 \times 10^{20}$ & $5 \times 10^{12}$ \\
\hline $\mathrm{C} 05$ & $\ldots$ & $2 \times 10^{15}$ & $5.5 \times 10^{14}$ & $2 \times 10^{20}$ & $5 \times 10^{15}$ \\
\hline Si_Ref & $\ldots$ & $\ldots$ & $\ldots$ & $\ldots$ & $\ldots$ \\
\hline
\end{tabular}




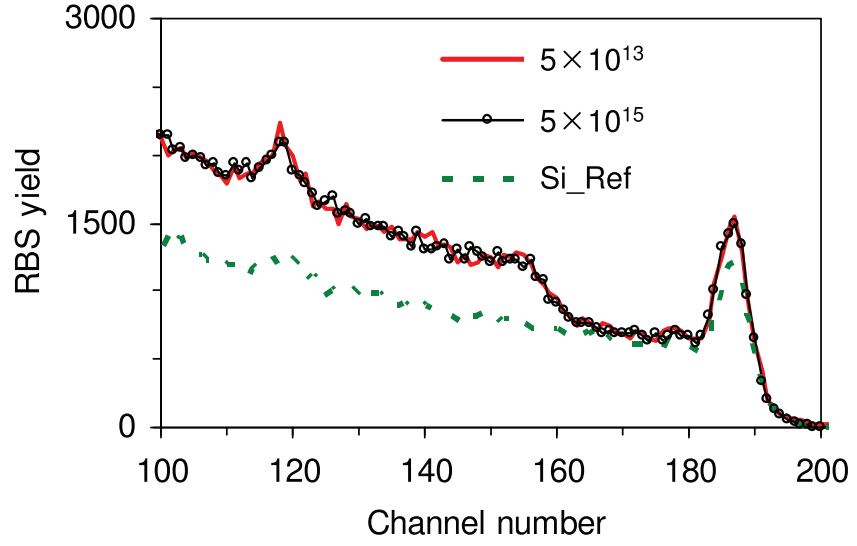

FIG. 2. RBS channelling spectra of pre-amorphised samples A03 and A05 $\left(2 \times 10^{20} \mathrm{C} \mathrm{cm}^{-3}\right.$ irradiated with $5 \times 10^{13}$ and $5 \times 10^{15} \mathrm{H}^{+} \mathrm{cm}^{-2}$, respectively), and of a virgin silicon (Si_Ref).

reference and $\sim 4 \mathrm{~nm}$ for the implanted samples) on the samples surface. Both pre-amorphised samples have a damage profile with higher yield than the reference sample, located immediately behind the surface Si peak. The damage yield comes from the radiation damage, mainly from $\mathrm{Si}$ atoms that are displaced from their lattice positions in collision cascades induced by the irradiation. The similarity of damage level observed in both proton irradiated samples, at $5 \times 10^{13}$ and $5 \times 10^{15} \mathrm{~cm}^{-2}$, indicates that the proton dose does not significantly affect the total damage created after the proton irradiation. The silicon interstitial yield at channel number $\sim 160$ in Figure 2 shows an increase for both proton irradiated samples when compared to the reference sample. The dislocation network resulting from the end of range (EOR) damage created by Ge implant can be seen clearly in both samples starting at channel number $\sim 150$. Therefore, it is possible to determine the location of the end of range damage by extracting the Si depth profiles, as shown in Figure 3.

The end-of-range defects are observed at a depth of $200 \mathrm{~nm}$ as seen in Figure 3. These defects are due to supersaturation of interstitials below the former amorphous/crystalline $(\mathrm{a} / \mathrm{c})$ interface after solid phase epitaxial regrowth. The EOR defects are confirmed by the TEM analysis carried out in a pre-amorphised $\mathrm{C}$ sample that was not proton irradiated,

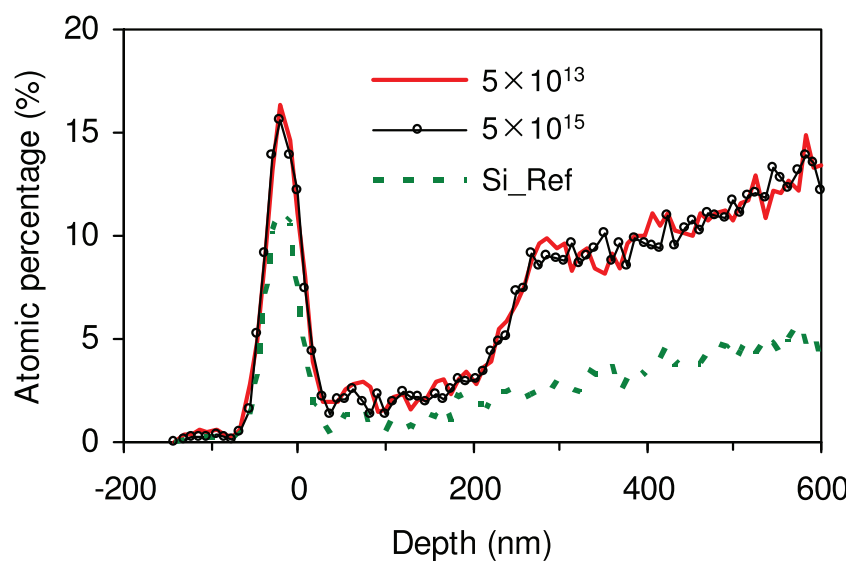

FIG. 3. Extracted Si depth profiles for the same samples A03 and A05 shown in Figure 2. End-of-range damage can be seen starting at $\sim 200 \mathrm{~nm}$ depth.

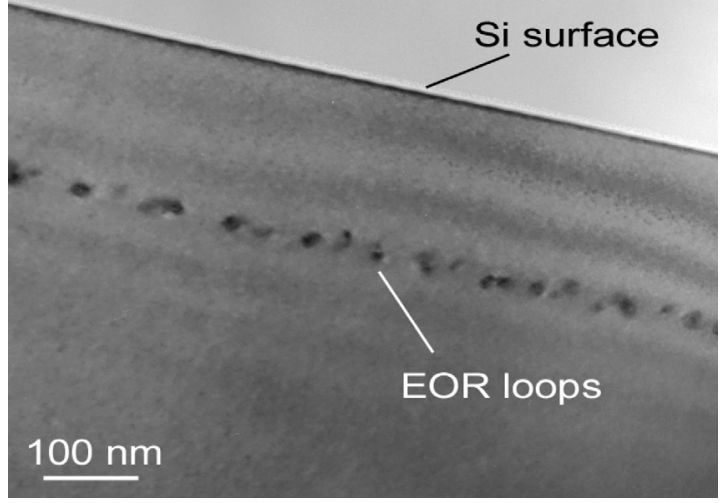

FIG. 4. Bright-field XTEM image taken along [110] Si of a pre-amorphised sample implanted with carbon to a volume concentration of $2 \times 10^{20} \mathrm{~cm}^{-3}$ (sample A0). The end of range dislocation network damage is seen at a depth of $\sim 200 \mathrm{~nm}$.

shown in Figure 4. The EOR defects can be clearly seen around $200 \mathrm{~nm}$ depth. Thus, the mean depth values of EOR defect that was calculated from RBS spectra is in good agreement with those obtained from the TEM analysis. Ge implantation at $180 \mathrm{keV}$ resulted in an a/c interface at $\sim 127 \mathrm{~nm}$ depth, calculated using stopping and range of ions in matter (SRIM); ${ }^{14}$ therefore, the EOR defects at $\sim 200 \mathrm{~nm}$ depth remain below the former a/c interface.

Photoluminescence spectra, measured at $80 \mathrm{~K}$, of samples without the pre-amorphisation stage are presented in Figure 5. Samples were implanted with carbon to volume concentrations ranging from $2 \times 10^{18} \mathrm{~cm}^{-3}$ to $2 \times 10^{20} \mathrm{~cm}^{-3}$ and then irradiated with $5 \times 10^{13} \mathrm{H}^{+} \mathrm{cm}^{-2}$ (samples $\mathrm{C} 83$, C93, C03). The PL spectrum of a sample implanted to $2 \times 10^{20} \mathrm{C} \mathrm{cm}^{-3}$ but irradiated with $5 \times 10^{15} \mathrm{H}^{+} \mathrm{cm}^{-2}$ is also shown (sample C05). The highest G-centre emission was observed in the sample implanted to $2 \times 10^{19} \mathrm{C} \mathrm{cm}^{-3}$

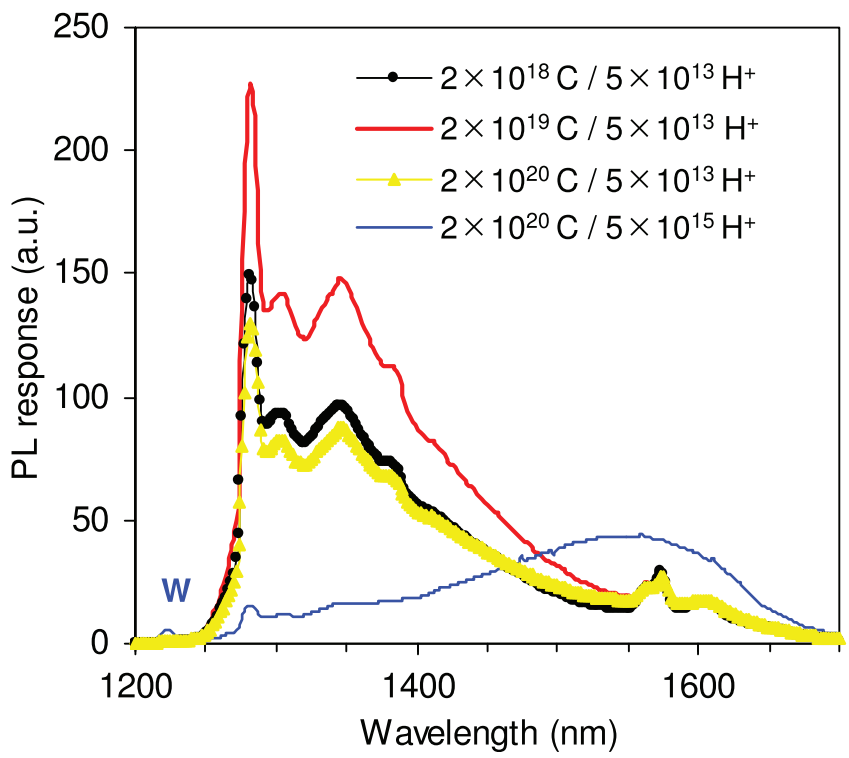

FIG. 5. Photoluminescence spectra, observed at $80 \mathrm{~K}$, of crystalline samples implanted to $2 \times 10^{18}, 2 \times 10^{19}$, and $2 \times 10^{20} \mathrm{C} \mathrm{cm}^{-3}$ irradiated with $5 \times 10^{13} \mathrm{H}^{+}$(samples $\mathrm{C} 83, \mathrm{C} 93$, and $\mathrm{C} 03$, respectively), and of a sample implanted to $2 \times 10^{20} \mathrm{C} \mathrm{cm}^{-3}$ irradiated with $5 \times 10^{15} \mathrm{H}^{+} \mathrm{cm}^{-2}$ (sample C05). The silicon band-edge emission at $\sim 1.1 \mu \mathrm{m}$ is absent in all spectra. The position of the W-centre is also shown. 
(sample C93). All the samples except sample C05 (irradiated with the highest proton dose) have similar PL features, with the G-centre dominating the spectrum. Sample C05 spectrum consists of a broad peak in the $\sim 1400$ to $1600 \mathrm{~nm}$ range, similar to the pre-amorphised sample irradiated at the same proton fluence (sample A05). The $\mathrm{C}_{\mathrm{i}} \mathrm{O}_{\mathrm{i}} \mathrm{C}$-centre is observed in all samples except $\mathrm{C} 05$. The $\mathrm{C}$-centre is due to carbon interaction with residual oxygen present in the substrate which initially competes with the G-centre formation but saturates once the oxygen is fully complexed. A weak $\mathrm{W}$-centre whose zero phonon photoluminescence peak is located at $1220 \mathrm{~nm}$ is observed in sample C05. The W-centre is attributed to self-interstitials defect clusters formed after ion irradiations. ${ }^{12}$ The presence of the $\mathrm{W}$-line indicates the existence of an excess of silicon interstitials created after the proton irradiation, which compete to form various silicon-related radiative and non-radiative centres, including the $\mathrm{W}$ - and G-centres.

Similar to pre-amorphised samples, RBS analysis was used to investigate the role of proton irradiation in the damage created and on the concentration of self-interstitials in the crystalline samples. Figure 6 shows the RBS channelling spectra of the same crystalline samples used for the PL measurements discussed above. As anticipated from the PL results, the sample with the highest G-centre's peak intensity exhibits the highest damage yield. The PL and RBS results are consistent with the G-centre's peak intensity proportional to the damage distribution and number of self-interstitials in the samples, especially for samples C83 and C93 which show increasing amounts of damage distributed through the channel. Highest silicon interstitial yield is observed in sample C93 implanted to $2 \times 10^{19} \mathrm{C} \mathrm{cm}^{-3}$ followed by $5 \times 10^{13} \mathrm{H}^{+} \mathrm{cm}^{-2}$ irradiation. We suggest that, at the implant energies used here, these carbon and proton doses are the optimum ones to achieve the highest G-centre luminescence. Implanting higher doses of carbon or proton will only result in the accumulation of excess silicon interstitials which consequently form clusters with each other, thus, lowering the probability of forming the G-centre complex. However, RBS

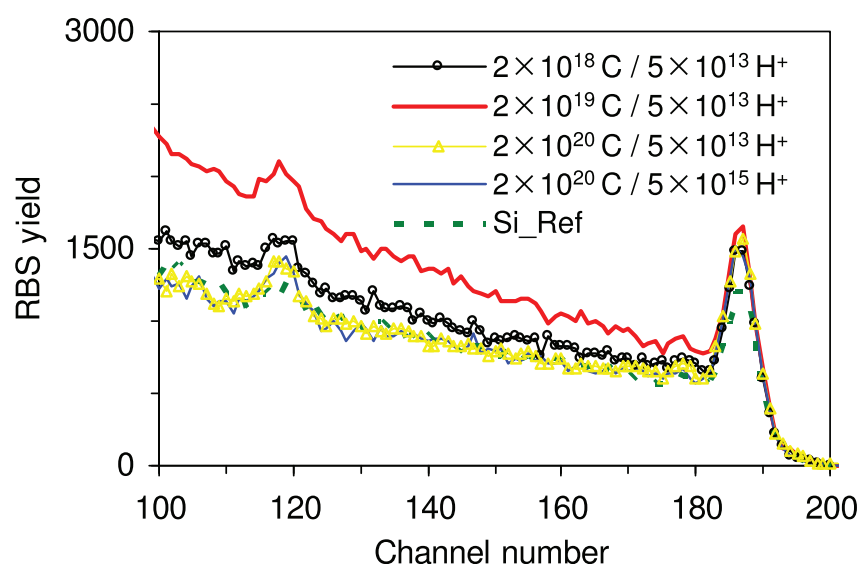

FIG. 6. RBS channelling spectra of crystalline samples implanted to $2 \times 10^{18}, 2 \times 10^{19}$, and $2 \times 10^{20} \mathrm{C} \mathrm{cm}^{-3}$ irradiated with $5 \times 10^{13} \mathrm{H}^{+}$(samples $\mathrm{C} 83, \mathrm{C} 93$, and $\mathrm{C} 03$, respectively), and of a sample implanted to $2 \times 10^{20} \mathrm{C} \mathrm{cm}^{-3}$ irradiated with $5 \times 10^{15} \mathrm{H}^{+} \mathrm{cm}^{-2}$ (sample C05). The spectrum of the virgin $\mathrm{Si}$ (Si_Ref) is also shown. results for samples $\mathrm{C} 03$ and $\mathrm{C} 05$, implanted to the highest carbon volume concentration $\left(2 \times 10^{20} \mathrm{~cm}^{-3}\right)$, do not show a significant difference of silicon damage yield compared to the reference sample. These two samples have increasing amounts of damage distributed through the layer with no well defined layer causing dechannelling. The dechannelling in the initial (rather thin) layer apparently causes continued dechannelling in the bulk of the substrate, indicating a distributed dislocation network.

The degree of apparent damage present in each sample can be determined by calculating the silicon interstitial yield with respect to the reference silicon sample using the RBS data shown in Figures 2 and 6. The value of the silicon interstitial yield is the difference between the area under the curves of an implanted sample and the virgin (reference) sample, calculated from channel 160 to 180 . Table II shows the silicon interstitial yield for samples C83, C93, C03, $\mathrm{C} 05$, A03, and A05, as well as the percentage of apparent damage (excess over the silicon reference) present in each sample. Sample C93 has the highest apparent damage in the modified layer and also gives the strongest emission at $1.28 \mu \mathrm{m}$ implying that this sample has the highest concentration of silicon interstitials which is essential in the formation of the G-centre complex. The lowest silicon yield is in sample C05 (highest carbon and proton doses). In this case, it is possible that the excess silicon interstitials resulted from the proton irradiation may have accumulated and formed the non-radiative defect centres. We note that both the highest and lowest silicon yields are from samples without pre-amorphisation. Samples C03, A03, C05, and A05, all implanted to $2 \times 10^{20} \mathrm{C} \mathrm{cm}^{-3}$, show that pre-amorphised samples give more silicon yield compared to samples without pre-amorphisation, thus suggesting that preamorphisation can enhance the formation of silicon interstitials in samples implanted with high carbon dose.

Figure 7 shows the TEM results of two crystalline samples implanted to $2 \times 10^{20} \mathrm{C} \mathrm{cm}^{-3}$. One sample was irradiated with $5 \times 10^{12} \mathrm{H}^{+} \mathrm{cm}^{-2}$ (sample C02) while the other was used as a reference and not irradiated (sample $\mathrm{C} 0$ ). The results of the TEM analysis revealed that carbon implantation at a very high dose is capable of producing a sufficient amount of interstitials which subsequently form dislocation loops in the silicon lattice structure at the mid range of the carbon implant. However, there is not a significant difference in the carbon induced dislocation loops density present in samples with and without the proton irradiation. This suggests that proton irradiation is not a major factor in the formation of the dislocation loops at higher carbon doses, as

TABLE II. Summary of the silicon interstitials yield and the degree of apparent damage (excess over the silicon reference) present in each sample. The yield was determined by calculating the difference between the area under the curve (channels 160 to 180) of an implanted sample and the reference sample. The yield is directly proportional to the damage in the samples.

\begin{tabular}{lcccccc}
\hline \hline Sample & C83 & C93 & C03 & A03 & C05 & A05 \\
\hline Si yield & 1863 & 4681 & 740 & 1452 & 287 & 1168 \\
Excess over Si_Ref (\%) & 16.6 & 41.7 & 6.6 & 12.9 & 2.6 & 10.4 \\
\hline
\end{tabular}




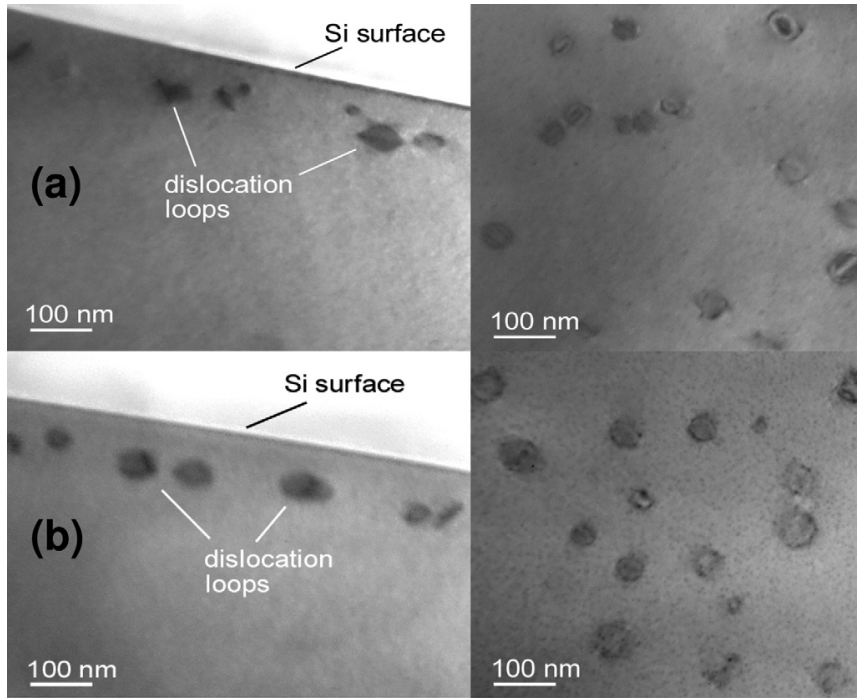

FIG. 7. Bright-field XTEM images taken along [110] Si and plan-view images taken close to [001] Si of (a) crystalline sample implanted with carbon to a volume concentration of $2 \times 10^{20} \mathrm{~cm}^{-3}$ (sample $\mathrm{C} 0$ ) and (b) of a crystalline sample implanted to the same $\mathrm{C}$ volume concentration and irradiated with $2 \mathrm{MeV}$ protons at $5 \times 10^{12} \mathrm{~cm}^{-2}$ (sample C02). The carbon induced dislocation loops are clearly seen in both samples at a depth of $\sim 100 \mathrm{~nm}$.

most of the interstitials were formed and agglomerated with each other after the carbon implant and subsequent anneal. We also note that no dislocation loops were found in the preamorphised sample implanted with the same carbon concentration (Figure 4). This opens up a new promising method of producing efficient luminescence in silicon structures which combines the dislocation engineering and point defect method. $^{15,16}$

\section{CONCLUSION}

RBS channelling and TEM experiments have been carried out to analyse carbon and proton irradiated silicon samples in order to explain and support the results of photoluminescence measurements. The analysis reveals that the silicon interstitials generated after proton irradiation are an essential factor in forming the G-centre complex. The highest silicon yield is found in samples without preamorphisation, consistent with the highest G-centre luminescence found in these samples. Pre-amorphisation influences the formation of damage by reducing the efficiency of the proton irradiation. However, at higher carbon dose, preamorphisation does appear to contribute to creating a higher silicon yield for the formation of the G-centre.

We have also found that dislocation loops can be formed after carbon implantation and a subsequent anneal. Dislocation loops can be used to enable efficient luminescence in silicon and reduce or eliminate the thermal quenching. By combining carbon implantation and high energy proton irradiation to form the G-centre with the controlled introduction of dislocation loops using either boron or carbon, it may be possible to obtain high intensity luminescence from the G-centre at high operating temperatures.

\section{ACKNOWLEDGMENTS}

We acknowledge the European Research Council for financial support under the FP7 for the award of the ERC Advanced Investigator Grant No. SILAMPS 226470.

${ }^{1}$ J. M. Bao, M. Tabbal, T. Kim, S. Charnvanichborikarn, J. S. Williams, M. J. Aziz, and F. Capasso, Opt. Express 15, 6727 (2007).

${ }^{2}$ E. Rotem, J. M. Shainline, and J. M. Xu, Proc. SPIE 6775, 17750 (2007).

${ }^{3}$ E. Rotem, J. M. Shainline, and J. M. Xu, Appl. Phys. Lett. 91, 051127 (2007).

${ }^{4}$ S. G. Cloutier, P. A. Kossyrev, and J. Xu, Nat. Mater. 4, 887 (2005).

${ }^{5}$ E. Rotem, J. M. Shainline, and J. M. Xu, Opt. Express 15, 14099 (2007).

${ }^{6}$ K. P. Odonnell, K. M. Lee, and G. D. Watkins, Physica B \& C 116, 258 (1983).

${ }^{7}$ D. D. Berhanuddin, M. A. Lourenço, R. M. Gwilliam, and K. P. Homewood, Adv. Funct. Mater. 22, 2709 (2012).

${ }^{8}$ R. P. Webb, suspre Version 2.1.3, Surrey Ion Beam Center, University of Surrey, http://www.surrey.ac.uk/ati/ibc/research/modelling_simulation/ suspre.htm, 2001.

${ }^{9}$ C. Jeynes, N. P. Barradas, P. K. Marriott, G. Boudreault, M. Jenkin, E. Wendler, and R. P. Webb, J. Phys. D 36, R97 (2003).

${ }^{10}$ G. Boudreault, C. Jeynes, E. Wendler, A. Nejim, R. P. Webb, and U. Watjen, Surf. Interface Anal. 33, 478 (2002).

${ }^{11}$ K. Thonke, H. Klemisch, J. Weber, and R. Sauer, Phys. Rev. B 24, 5874 (1981).

${ }^{12}$ G. Davies, Phys. Rep. 176, 83 (1989).

${ }^{13}$ C. G. Kirkpatrick, J. R. Noonan, and B. G. Streetman, Radiat. Eff. Defects Solids 30, 97 (1976)

${ }^{14}$ J. Ziegler, J. P. Biersack, and U. Littmark, The Stopping and Range of Ions in Matter (Pergamon, New York, 1985).

${ }^{15}$ W. L. Ng, M. A. Lourenço, R. M. Gwilliam, S. Ledain, G. Shao, and K. P. Homewood, Nature 410, 192 (2001).

${ }^{16}$ M. Kittler, M. Reiche, T. Arguirov, W. Seifert, and X. Yu, Tech. Dig. Int. Electron Devices Meet. 2005, 1005. 